\title{
Public Injecting Drug Use and the Social Production of Harmful Practice in High-Rise Tower Blocks (London, UK): A Lefebvrian Analysis.
}

\begin{abstract}
This paper presents, qualitative findings relating to specific environments hitherto unrecognised as settings used for the injecting-use of illicit drugs in an urban setting. This concerns the temporary appropriation of communal space within high-rise social-housing by injecting drug users (IDU); specifically those settings used by tower-block residents for garbage disposal ('bin chute rooms').

These environments were found to be used on daily, habitual bases by all IDU interviewed during the study. Such settings were found to contribute to a wide range of injecting-related harm and hazard. These findings further debate concerning the negative of effect of place on health risk in the context of 'public' injecting drug use.

These results are further situated within a theoretical framework forwarded by Henri Lefebvre, concerning the social production of social space. It is contended that the 'representational spaces' shaped by IDU creates a dialectic between wider 'spatial practice' and 'representations of space'. Accordingly, it is further suggested that particular 'spaces' of harm reduction (such as 'safer injecting facilities') should be considered in UK settings in order to minimise injecting-related harm.
\end{abstract}

Keywords: public injecting drug use; harm reduction; high-rise tower blocks; rights to the city; Henri Lefebvre; injecting-related harm; 


\section{Public Injecting Drug Use and the Social Production of Harmful Practice in High-Rise Tower Blocks (London, UK): A Lefebvrian Analysis.}

The term 'public injecting drug use' is perhaps paradoxical. Although it is an expression used to describe the injecting use of illicit drugs in places frequented by a wider (non-drug-using) population, typically within public settings (such as public toilets, parking lots, shopping malls and railway sidings), the paradox lies in the concealed and marginal nature of the actual injecting episode. The overall motivations for participation in public injecting have been established as a response to 'situated necessities' (such as homelessness, drug cravings/ dependency, and/or opportunity) (Rhodes et al 2007; 276). Similarly, the rapid, concealed practice of drug preparation and ingestion have also been described as logical responses by injecting drug users (IDU) to avoid interruption and detection by members of the public and police respectively (Fitzgerald 2005). Public injecting sites therefore occupy zones of liminality (Dovey et al, 2001, 324) that are essentially away from a 'public gaze' whilst simultaneously situated within a public space. As such, public injecting drug use is, paradoxically, hidden whilst in open view.

\section{Public Injecting: hidden harm in public settings}

Numerous studies have found that public injecting is positively associated with a variety of drug-related harms (e.g. Klee and Morris 1995, Darke et al 2001, Debeck et al 2009, Hunt et al 2007, Marshall et al 2010, Parkin and Coomber 2010). These harms include fatal (and nonfatal) overdose, cerebral hypoxia, as well as needle trauma and vascular damage following inappropriate administration procedures. Other harms and injuries relate to those associated with femoral/neck injecting, peer-injecting (and peer-mediated injecting injury) and by polydrug use (involving mixtures of heroin, crack-cocaine, benzodiazepines and alcohol) or of 
solutes containing environmental adulterants (such as soil, cigarette ash) that produce socalled 'dirty hits' (Fry 2002, McKnight et al 2007, Parkin 2009, Parkin and Coomber 2009b, 2010). Public injecting sites (PIS) may also be settings considered unsuitable for conducting sterile injections. In such conditions IDU may share injecting paraphernalia (cookers, filters, water) and distribute drug solutes to injecting partners with previously used syringes (Bourgois and Schonberg 2009, Gossop et al 1997, Rhodes et al 2008, Taylor 2004, 2006). Others have noted that IDU accessing PIS may also receive used needles and syringes from other injectors or re-use discarded equipment found at such locations (Friedman 1998, Green et al 2003, Klee and Morris 1995, Navarro and Leonard 2004, Parkin 2009) with such behaviour posing significant opportunities of viral transmission (Green et al 2003), in which 'persistent public injection (is) independently associated with elevated HIV risk behaviour' (McKnight et al 2007; 319).

\section{Public Injecting and Theoretical Contributions}

Despite this corpus of research that specifically describes harm associated with public injecting, there have been relatively few attempts at theorising this injecting drug use phenomenon. Notable exceptions to this critique however would include the 'risk environment' thesis (Rhodes 2002, Rhodes et al 2005) and a 'theory of lumpen abuse' (Bourgois and Schonberg 2009) in which various scholars frame harm and hazard as a consequence of various social structures impacting upon human agency. Similarly, in previous papers, we have presented empirical research findings that demonstrate similar structuration theories put forward by Pierre Bourdieu; most notably that of habitus, field and practice (Parkin 2009, 2010, Parkin and Coomber 2009b, 2010). In this paper however, we prefer not to draw once more upon previously applied Bourdieusian theory, and instead consider the work of Henri Lefebvre (1991) to demonstrate that socially produced spaces 
construct harmful practice. This contribution has been informed by ethnographic research situated within shared public spaces of residential tower blocks throughout a London Borough during 2010. In providing this interpretation of Lefebvre's thesis of space and place, we aim to make explicit the social production of health harm associated with concealed environments of public injecting drug use.

\section{The Social Production of Space}

Lefebvre's (1991) thesis on the construction of place contends that '(social) space is a (social) product' (Lefebvre, 1991: 26) in which the use of space serves to shape thought and action as well as provide a means of social control via the re/production of accepted practice within place per se. This control is maintained by 'a conceptual triad' (ibid: 33) of 'spatial practice', 'representational spaces' and 'representations of space'. 'Spatial practice' determines social cohesion and informs social membership within particular settings due to the widerrecognition of social boundaries and accepted behavioural norms (i.e. how space is actually used). 'Representational space' however is that which is conceptualised by individuals, involving independent perceptions, conceptions and contestations of space (i.e. how individuals believe space should be used). Whereas these constructs of space relate to ordered and appropriated behaviour respectively (Mitchell 2003, Hockey 2010), the 'representation of space' corresponds to the way in which places are designed, controlled and furnished (why space is made). In short, the acceptance of these spatial codes of conduct creates a 'spatial economy' that 'valorises certain relationships between people in particular settings' (Lefebvre 1991: 56) and establishes consensual behaviour deemed appropriate (or otherwise) for such locations. 
As noted by Mitchell (2003) the 'right to the city' is a slogan that is closely associated with Lefebvre and relates to the view that cities are shaped and formed by the participatory actions of citizens. In this manner, public spaces are 'produced' by the heterogeneity of citizenship and, by definition, are characterised by social exchange and, more significantly, by social 'difference'. Lefebvre further notes that for such a heterogeneous project to succeed (and for difference to co-exist), struggle and conflict will emerge in relation to the contested ownership and control of 'public' environments. From this struggle however, 'new modes of living and inhabiting are invented' (Mitchell 2003; 18) and 'city-spaces' evolve from the respective rights (and responsibilities) of citizenship.

This theory of the production of space is illustrated by Mitchell's (2003) account of People's Park (Berkeley, California) in which public space that had become a refuge for the city's displaced and dispossessed was subject to 'reclamation' and made more accessible to (and for) a more 'appropriate public' (ibid, 122). At the core of Mitchell's account is the Lefebvrian notion of a right to the city in which homeless people are denied access to public space, active citizenship and intimate conduct within appropriated places. That is, representational space is seen to conflict with representations of space in which the former becomes subject to regulation, restriction and social control by more dominant structural forces.

Mitchell is not unique in this respect and several others have provided similar Lefebvrian critiques of city space and/or urban design. Such accounts typically relate to social/political sectarianism (e.g. Nagle 2009, Fawaz 2009), and/or racial/cultural division (e.g. Layard 2010; McCann 1999) but each typically serve to demonstrate the heterogeneity and multi-faceted productions of space in contemporary settings. Perhaps a more succinct interpretation may be 
noted in Beltrano’s $(2009$, 42) visual depiction of a vendor selling produce from makeshift cardboard tables on the sidewalk of urban Toronto (Canada). With Beltrano's image, Lefebvre's notions of urban heterogeneity and 'rights to the city' are made apparent as are the concepts of contested and appropriated space.

\section{Demonstrating Socially-Produced Harm within Public Injecting Sites}

Lefebvre's interpretations of space and the right to the city therefore appear pertinent to the issue of injecting environments that are situated in the shared public spaces of residential tower blocks. Accordingly, presented below is an account of injecting drug use within 'bin chute rooms' (communal areas used for waste disposal) and how these settings produce a consistent and particular 'social space’ (Lefebvre 1991) for local IDU networks. More significantly, we seek to further demonstrate the effects of place (environment) on health risk with the application of Lefebvrian theory. This demonstration of socially-situated harm concerns the contestation and appropriation of shared public space within the residential settings of a particular working class area of London (UK).

\section{The Study}

The findings described below have emerged from an initiative known as the Public Injecting Rapid Appraisal Service (PIRAS) within the University of Plymouth (Parkin, Coomber and Wallace 2010). PIRAS aims to conduct localised studies of public injecting drug as applied, research with service value. Similarly, PIRAS-related findings aim to be translated into intervention and initiatives that prioritise community safety/public health development. 
In March 2010, Barking and Dagenham Drug and Alcohol Action Team (DAAT) ${ }^{1}$ commissioned a six-month evaluation of public injecting as part of the PIRAS initiative. The London Borough of Barking and Dagenham is one of 32 local authorities (throughout London) responsible for organising, commissioning and managing local services for local people. Although separated by a physical distance of approximately 4miles $(6 \mathrm{~km})$ the two distinctly different communities (socially, spatially and culturally) of Barking and Dagenham together form a single area of local authority with a shared municipal council. According to 2001 census data, Barking and Dagenham (BD) has a population of approximately 165,000, of which approximately $85 \%$ are described as white, British. The Borough has a rich history that accommodates a $7^{\text {th }}$ century Abbey, one of Europe's largest social-housing estates and a once thriving, (now redundant), motor manufacturing industry. This working-class social history is emphasised in the 2010 movie Made in Dagenham (charting the equal opportunities movement in factory settings). In the May 2010 general election, the British National Party was removed as the main opposition party in the Borough.

\section{Method}

The PIRAS initiative is a research package that applies rapid appraisal methods as part of qualitative inquiry into drug-related issues. Accordingly, the 6-month study was informed by semi-structured interviewing; reflexive field accounts, visual methods (photography), environmental visual assessments (visits to injecting areas with agency representatives and injecting drug users) and participant/direct observation as part of the ethnographic design of PIRAS. Each of these methods were conducted with a sample of 63 agency representatives that were familiar with public injecting issues (security guards, cleansing staff, caretakers etc) as well as a with 20 IDU at various stages of individual drug-using careers (whether 'current

\footnotetext{
${ }^{1}$ A body that is responsible for the management and delivery of the national Drug Strategy (HM Government 2008) at a local level
} 
user', 'in recovery', or 'abstinent'). The methods described in previous public injecting research (Parkin and Coomber 2009a, 2009b, 2010a) were thus transferred and replicated in a different geographical setting (Pearson, Parkin and Coomber 2011). Table 1 below summarises the range and rationale for employing the various qualitative methods throughout the study.

\section{<Table 1 Here> <see Appendix 1>}

\section{The Injecting Drug User (IDU) Sample}

All IDU were recruited from one of two settings, both of which were dedicated, open-access, drug agencies that provide a range of harm reduction services to respective clients (including injecting equipment, access to treatment services, counselling, advocacy and other support). All interviews with IDU were audio-recorded and took place in private rooms within the above settings in order to maintain confidentiality and anonymity. All respondents provided verbal informed consent to participate in the study and each were provided with an honorarium (£10) for completing the interview. All research was ethically approved by the University of Plymouth’s relevant Faculty Research Ethics Committee.

Of the IDU sample, 50\% reported ‘coming from’ Barking and 50\% from Dagenham. From Table 2, it may be noted that a typical male respondent was aged 36, white British, from the local area, unemployed (and/or in receipt of welfare). Similarly, a typical female respondent was aged 31, white-British and also from the local area. Both male and female respondents typically reported lifetime experience of homelessness (90\%, 18/20) and almost 70\% (14) of the sample had served prison sentences for drug-related offences. 
Overall, the sample was characterised by socio-economic marginality, unstable accommodation and long-term, heroin-injecting careers (Table 3). All 20 (100\%) respondents had a lifetime experience of injecting in public settings in BD. Many of those interviewed were attempting to recover from heroin dependency by means of substitute prescribing, but were also using illicit drugs (principally heroin) as a means of supplementing what was generally perceived (by the relevant IDU respondents) as insufficient levels of medication (i.e. resulting in continued, supplementary, use of street-heroin). Experience of overdose (whether personal or witnessed) was also widespread throughout the sample, with almost 50\% having 'ever experienced' overdose in an outdoor setting in Barking and/or Dagenham. Finally, blood borne virus was noted within this population, in which 30\% (6) were living with hepatitis $\mathrm{C}$ and 5\% (1 person) with HIV. From these data it can be further concluded that the social, economic and health profile of the IDU sample is both consistent with, and similar to, other IDU populations that attend PIS in other (national/ international) locations (Darke et al 2001, Fitzgerald et al 2004, Green et al 2003, Klee and Morris 1995, McKnight et al 2007, Navarro and Leonard 2006, Parkin and Coomber 2009b, 2010, Small et al 2006, Taylor et al 2004, 2006).

\section{$<$ Tables 2 and 3 here $><$ See Appendix 2 and 3>}

\section{Public Injecting in Shared Spaces of High-Rise Flats ${ }^{2}$}

Perhaps the most significant finding was the reported incidence and frequency of public injecting drug use in the shared spaces of high-rise flats (HRF) throughout the London

\footnotetext{
${ }^{2}$ It is important to stress that this form of rented social housing, throughout the UK, is typically found within working class neighbourhoods; usually accommodating low-income and/or welfare dependent families. This form of housing emerged nationally during post-war (1939-45) regeneration projects, replaced former slum dwellings throughout Britain and was initially envisaged as creating 'streets in the sky'. Since their development however, many estates comprising of such high-rise social housing have become characterised by overcrowding, deprivation and other social problems. Indeed, contemporary regeneration schemes in many UK cities often include the demolition of such housing that has since been termed 'slums in the sky' (Hanley 2008; 97).
} 
Borough of Barking and Dagenham. This issue was found to be the single most important (and consistently raised) issue throughout the study - from the perspectives of agencies and IDU.

\section{Defining Shared Space}

Injecting drug use within the shared communal spaces of HRF typically took place upon stairwells, within garbage units and cupboard-like rooms containing electricity meters. However, the most preferred, most cited and most regularly attended venues for all current/previous public injecting drug use by all 20 (100\%) IDU respondents were the 'bin chute rooms’ (BCR) within residential tower blocks.

Bin chute rooms are located on each and every floor (or landing) within HRF. These small rooms serve to provide communal space on each floor for a number of flats (usually 4-6 households) for the purposes of general waste disposal. BCR essentially house a single vertical shaft that can be accessed by a metallic hatch (see Photograph 1). Once the latter is open, garbage sacks can be dropped into the shaft, to be collected in a large waste receptacle on the ground floor (i.e. at the base of the 'chute'). Doorways to BCR are typically open and remain unlocked on a permanent basis to provide unrestricted access for the relevant residents. The following field note typifies the environmental and spatial setting of BCR:

(it) measured approximately 8 feet by 5 feet by 6 feet with no windows and was lit by a dim fluorescent light bulb. ... Although it was not a 'dirty place' - it wasn't exactly clean (but) from a hygiene perspective, there were limited surfaces, poor lighting, in a dark, dusty environment, with no running water and nowhere to prepare solutes safely. 
(Field Notes, May 2010, 'Walking tour’ of PIS with Respondent 007)

\section{<Photograph 1 here $><$ Appendix 4>}

\section{Bin Chute Rooms: Socially Constructed Injecting Spaces}

All 20 (100\%) of the IDU sample had a lifetime experience of injecting and/or smoking illicit substances in BCR throughout Barking and Dagenham. Similarly, all had accompanied other injectors, as well as attended such settings alone. Indeed, BCR were widely regarded throughout the sample as places that had become so established within the local IDU fraternity that they had become 'normalised' settings of substance use (i.e. they were not regarded as unusual or unique places for drug administration, whether smoking / injecting heroin and/or crack-cocaine). As one respondent explained, 'all drug users know round here to use the chute rooms, cos they ain't got no other place to go to' (Respondent 004, original emphasis). For these reasons there was perhaps a certain irony in the abbreviation used by residents and agencies to describe these settings: namely, 'chute rooms'.

Due to the huge volume of qualitative data collected on injecting drug use in BCR, the following account prioritises themes relating only to matters of a health-place nexus. These themes have been organised into the following categories: 'rationale and access', 'drug preparation and injecting hygiene’, 'overdose’ and 'harmful/hazardous injury’.

\section{$\underline{\text { Rationale and Access }}$}

The range and availability of generic public settings for injecting drug use throughout the Borough was observed (by SP) and described (by IDU) as limited due to increased public security, high-visibility policing and the spatial organisation/design of both Barking and 
Dagenham. For these reasons, the IDU sample was of the view that BCR provide needful, temporary settings within familiar, concealed environments, where drugs could be injected privately and/or urgently with minimal opportunities for interruption (by the public) or detection (by police). These motivations further reflected a need to immediately address any withdrawal symptoms (relating to drug dependency) or an impatience to satisfy opiate-related cravings. In addition to these 'drug-related' motivations were those concerning a lack of secure accommodation, homelessness or a need to hide injecting from relevant others (partners, family, children) - each of which required concealing and participating in injecting drug use within street-based settings. Accordingly, BCR provided viable alternatives to the general lack of public toilets, parking lots and other settings throughout BD that have been found to typically house public injecting activity in other urban settings (Parkin 2009).

The above motivations typify the rationale for IDU accessing BCR, whether resident in Barking or in Dagenham. Each geographic location provided further opportunities for injecting in HRF due to the close availability of particular drug markets, occasionally within the same building. As such, BCR provided opportunistic places for injecting as they were typically located within a supply-place triumvirate due to their proximity to the places to obtain drugs (markets and sellers) and the outlets providing the means to inject drugs (local pharmacies providing injecting equipment). Attendance in BCR for injecting purposes therefore represents a natural progression of participation in this socio-geographic, placesupply nexus (i.e. moving linearly and progressively from one environment to the next; from pharmacy/seller to seller/pharmacy to BCR). It is also noteworthy that Dagenham-based IDU stated they would on occasion travel to Barking to purchase drugs (and use BCR in Barking in such an opportunistic manner), whereas none of the Barking-based IDU reported travelling to Dagenham to purchase/inject drugs. Nevertheless, those of Barking stated that they would 
also use BCR within tower blocks that were not necessarily the places where they personally resided. Each of these local factors relating to the above seller-place nexus establish Lefebvre's concept of 'representational space' in which BCR settings have been geographically and culturally appropriated by local populations of IDU for injecting purposes.

At the time of fieldwork (May-July 2010), the most cited setting for BCR attendance were those tower blocks nearest and/or adjacent to Barking town centre. Although consisting of 13 individual HRF, those interviewed did not (or refused to) state a preferred building for injecting drug use. However, the most cited response was that it could occur 'anywhere' throughout the housing stock and was largely dependant upon where drugs were purchased; who the respondent was with, the proximity to their own residence and how familiar the location was to each individual concerned. Nevertheless, a common theme emerged that those accessing particular BCR were not necessarily residents of particular HRF chosen for injecting purposes. For these reasons, various accounts were given that summarised the way in which IDU gained access to secure, residential properties. These included: contacting a known associate (whether other IDU or drug seller) already resident in the building (by mobile telephone or using the ‘intercom' entry system), randomly pressing ‘doorbells' and requesting permission to enter from those that answered (i.e. opportunistic use of the ‘intercom’ system), gaining access when main doors became open as residents leave/enter the building and/or gaining access via unlocked fire / rear entry doors.

The following ethnographic fieldnote perhaps demonstrates the relative ease with which nonresidents may access HRF: 
We stood loitering outside one block and waited for the main door to be opened by a resident leaving/entering. This did not take too long, and the door was held open for us when we followed an elderly woman entering the building. We went down a corridor that led to a fire exit and (respondent) told me to see if it was locked. It wasn't and the door opened with a slight push. 'See, easy, you don't even need to come in the front, just go round the back to the fire escapes' he explained. We walked up the stairwell to the 2nd floor and within these walls our voices and footsteps seemed amplified a thousandfold. I tried lowering my voice in order to avoid others hearing what we were talking about. (Respondent) however stated that this illustrates how easy it was for IDU already within BCR to hear others approaching. This naturally-occurring echo therefore provides an ‘early warning system' of approaching others and alerts IDU of potential interruption.

(Field Notes, May 2010, 'Walking tour' of BCR with Respondent 007)

Once inside the building, wider decisions relating to which floor/landing IDU chose to attend for drug administration appeared at first sight to be completely arbitrary. However, each respondent had a particular preference, that was greatly influenced by the presence of others (whether caretakers, other drug users, residents or police officers). For example, some of the sample preferred to use the lower floors (where choice related to an urgency or impatience to address withdrawal symptoms or cravings), others preferred the mid-level floors (feeling 'safer' from interruption/detection on floors 4-6) and only a select few preferred the higher landings (i.e. floors 7-17, as these floors were considered 'unsafe' in terms of detection and 'escape'). Regardless of floor/landing chosen, BCR could then be freely accessed due to the 
'open door' policy applied throughout all HRF. In this manner, individual, pairs and groups of IDU (sometimes up to 6 people) accessed the BCR of HRF on a daily basis.

In Lefebvrevian terms, these aspects of producing space by IDU illustrate a subversion of space towards the appropriation of re-constructed, reconstituted, places that perhaps characterise the 'rights to the city' in attempts to accommodate 'difference'. Similarly, the selection of particular floor space (landings) and the sensory association of place demonstrate further the notion of representational space in attempts to address illness and/or dependency, whilst accessing secure and secluded spaces for injecting purposes.

\section{Drug Preparation and Injecting Hygiene}

Although BCR were preferred settings by IDU due to their relative privacy, concealment and silence, interviews and observations of these settings concluded that they are not conducive to the sterile preparation of substances to be injected. As noted above, BCRs are typically small enclosures designed with the specific intent of disposing household waste. From a harm reduction perspective, such settings compromise drug preparation procedures as there are no amenities for arranging paraphernalia upon sterile, metallic surfaces; no access to running water, reduced lighting and the constant possibility of interruption/detection by the public and/or police.

Accordingly, many of those interviewed described preparing drugs in rooms characterised by the pungent smells of household waste, urine and even human excrement. All available surfaces were considered unclean and 'dirty' and many described a process of ‘improvisation’ involving balancing drugs and paraphernalia on limbs whilst crouched on the 
floor. In settings devoid of sanitation and running water, harmful alternative procedures emerged. For example:

I've been in a bin chute with someone and we didn't have no water and he was sick, but he had a little bottle of Jack Daniel's whiskey in his pocket. He took it out, put his works in and pulled it up to 90 mil. I said, 'what the fuck you doing bro?' And he said, 'I'm having a hit' (using whiskey instead of water as the solute).

(Respondent 001)

Most of those interviewed recognised the importance of cleanliness and hygiene as part of drug preparation, but their use of BCR was equally recognised as practice that was counter to basic harm reduction advice. There was recognition that drugs were prepared and used in environments designed for waste disposal. This irony was not lost and several commented upon symbolic, spatial associations of selfhood with 'germs', 'bacteria', 'hep C' and of the anxiety associated with accessing places in order to 'open wounds where someone else has already opened up a wound' (Respondent 013). For one individual, it was this absence of cleanliness and hygiene within BCR that was directly attributed to an incidence of blood poisoning. Namely:

I actually caught blood poisoning. ... I wasn't keeping myself too (clean), obviously living rough and stuff, and I injected in a chute room. And a couple of days later I come down with cellulitis blood poisoning. I nearly lost my leg. I (injected) in my foot and probably because I had my shoes and socks off in a dirty place it must have been that, that must have done it. 
These adaptations to appropriated space reflect a structural prohibition in conducting private, intimate acts of self-injection. In subverting public space in this manner, IDU are participant in acts of resistance (i.e. asserting their 'rights to the city') that are situated within concealed, unsanitary settings.

\section{Injecting Technique}

Injecting technique within BCR was consistently described by the entire sample as a process characterised by haste. This rapidity had a direct correlation with a need to address withdrawal symptoms or drug cravings, whilst avoiding detection and interruption and simultaneously recognising that there was often no legitimate reason for being within particular tower blocks. For these reasons, there was a need to 'hit and run' in order for individuals to both 'feel well' again and to vacate the relevant premises as quickly as possible in order to avoid challenges from residents, janitors and/or police. Accordingly, several IDU described various psychological states that characterised injecting in BCR. These states (i.e. within an already substandard injecting environment) included anxiety, fear, nervousness, paranoia and excitement in which each contributed towards an injecting technique premised upon urgency. This ‘hit and run’ mentality may be noted in the following:

Because you're in a hurry to get it in you, obviously you don't want to be stopping in there longer than what you need to be ... in case you get caught. You know, you just thank your lucky stars basically that you've managed to get it in 
you, without somebody coming in on you. ... Then you go out, use your nous ${ }^{3}$, and sit outside on a bench or something ...

(Respondent 008)

From a harm reduction perspective, these mental states of mind may generate physically injurious consequences - especially when coupled with accelerated injecting procedures. Indeed, this view may be confirmed by the experiences of the IDU sample who each described various techniques that produced varying degrees of harm. For example, individuals accessing BCR alone described the following harmful procedures as a means of reducing time spent within the relevant HRF; femoral (groin) injecting, the multi-use of single use needles (up to three times per needle) and 'slamming' syringe plungers once needles were positioned in veins/injecting sites.

Similarly, those attending BCR as part of a pair / group of IDU described various behaviours that were equally shaped by a need to inject rapidly to minimise the time spent in HRF. These tactics included multi-person preparation of drugs and peer/neck injecting. However, the latter strategy was found to produce the following harmful consequences:

(While injecting into my neck), he said, “I haven’t seen it go like this (before). Look, look, look.” But how can I fucking look, do you know what I mean, it's in my neck! And I said 'you're fucking killing me, you're missing me’. He said, 'no, no, no, it ain't, it ain't', and whoosh, all your neck starts to blow up (And I'm going) oooh, oooh (sharp intakes of breathe). I can't breathe, can't hardly breathe, you know? And that was it. I got rushed to hospital and had to have an emergency

\footnotetext{
${ }^{3}$ A colloquial term meaning 'common sense'
} 
operation. I had a great big hole in my neck. It was massive. But at the time you don't give a fuck ... You really don't care.

(Respondent 020)

In this respect, rapid and rushed injecting procedures may be regarded as a need to preserve and protect representational spaces of drug administration. For those IDU accessing BCR there is recognition that their presence is not legitimate and that there is a need to vacate 'socially produced' injecting spaces as quickly as possible in order to preserve continued attendance and to avoid detection.

\section{Direct Sharing (of Previously Used Needles)}

2/20 (10\%) respondents disclosed details of providing previously used needles to others within BCR. These individuals claimed never to have 'received' used needles but would provide their own used equipment to others in circumstances such as the following:

They (receive used needles) because they ill. They ill and they want a bit of gear. ...You got a bit of gear and you're cooking up your gear, they don't want to smoke (it). ... They're looking round and they can't find no works. ... So they'll wait till I'm finished what I'm doing and I'll give em it with the blood in it! Give it to them and they think they're rinsing it out with cold water from the amp - but there's no hot water in the bin shed and they want the gear now, so they'll rinse it out about 10 times and use about 5 water amps thinking it's clean. ... So they try to ... what's the word ... justify it, by trying to make it OK, cos they'll say to me after they've rinsed it, they'll say, 'you aint got nothing have you anyway?' 'Course I have bro! Just a bit of Hep C and a bit of Hep B, but apart from that, I'm 
alright bro!’ And they say, 'Oh, you’re having a laugh!’ Yes, I am having a laugh bro, I'm Hep C and Hep B. ... but they're clucking so they'll pull it up, shoot it and try all what they can (to clean the works) with cold water.

(Respondent 001)

Similarly, 2 (10\%) other respondents disclosed details of receiving used equipment from IDU within BCR. Both of these individuals each reported positive hepatitis $\mathrm{C}(\mathrm{HCV}+)$ and attributed their previous needle sharing to this viral status.

From these data, it is perhaps noteworthy that at least 4/20 (20\%) respondents were willing to disclose details of direct needle sharing - despite an awareness of harm reduction, the need to avoid used paraphernalia and associated sharing with other IDU. That is to say, there was a recognised 'cultural unacceptability' throughout the IDU sample of paraphernalia-sharing, but despite this it was, nevertheless, an activity that continued to occur within specific injecting environments.

Such needle sharing may be understood as a response to the rapid ingestion of drugs in settings with limited resources and/or as an immediate response to addressing withdrawal symptoms. In Lefebvrian terms, this rapid sharing of needful resources further demonstrates the transitory and impermanence of physical spaces that are socially re-constructed in opposition to dominant representations of space. That is to say, socially constructed places produce harmful practice as a direct response to the illicit nature of substance use and the absence of legitimate, state-sanctioned injecting spaces. These harmful acts of reciprocity and altruism may also be contextualised within the socio-spatial networks and relationships of the IDU sample. That is, throughout all interviews, most respondents described altruistic 
relationships with other IDU (peers, family members) in which a common bond was injecting particular drugs in shared injecting environments. As such, pairs/collectives of IDU may have worked, lived and/or slept together whilst simultaneously knowing and safeguarding one another in public environments. In simplistic terms, participation in and membership of these relationships (and social networks) perhaps prioritise 'trust and friendship' over 'risk and danger' and is a premise based upon an 'assumed knowledge' of injecting partners. This may be illustrated with the following hepatitis risk-management strategy:

We'd both cook it up in the (same) spoon. Obviously, where we all know each other, we all know who's got Hep C and who ain’t, do you know what I mean? Like with my aunty. She'll say, 'OK, you know I’ve got hep, so you gotta draw up the gear first so you don't get it'. We're always honest with each other like that.

(Respondent 003)

\section{Overdose}

Almost half (45\%) of respondents had personal experience of drug-related overdose in an outdoor setting located in either Barking or Dagenham, with most episodes occurring within the vicinity of a particular tower block used for injecting purposes. Of further significance is that almost two thirds (65\%) of the sample had witnessed overdose in an outdoor setting in local settings throughout BD. For these reasons it was not uncommon for respondents to report the prioritisation of overdose aversion over other injecting-related risks (such as those described above). The collective avoidance of overdose was even described by several of the sample in terms of an IDU 'code of conduct' in which there was an 'unspoken' protocol within peer groups for helping others in the event of drug-related overdose. For example: 
... if you choose to inject, if you go over, we will take you outside, we'll phone the ambulance, we'll get you the ambulance and then we'll leave you. ... it's like a little code. Everywhere is the same. It's everywhere (not just Barking, but throughout the UK)

(Respondent 008)

Despite the unwritten 'code' noted above, there was a wide range of responses reported by the sample regarding personal experience of witnessing another 'going over' whilst attending BCR. In summary these responses included:

- No response and providing no assistance. In such circumstances the person experiencing overdose was 'only a face' and not part of an immediate social network.

- Minimal assistance provided: emergency services called and the respondent left the scene as soon as possible (with some waiting for the ambulance to arrive whilst observing events from afar).

- Maximum possible assistance including the provision of basic first aid (recovery position, mouth to mouth resuscitation, heart massage). In such circumstances, those concerned were described as long term, close friends.

Although several respondents stated they had experience of providing no assistance and leaving the scene of an overdose as quickly as possible, only one reported having been left in such a potentially fatal position. This event is summarised below and is included here in order to further illustrate resident assistance to IDU in BCR; breaking the 'code' (or 'safety net'), the harms associated with peer injecting, uncertain purity and polydrug use as well as the subsequent retributive action that may follow 'overdose-related abandonment': 
(I was found by) by one of the neighbours. I'd OD'd in (the bin chute room) and if it wasn’t for him I'd most likely be dead now. ... I was with this geezer ... But he injected me and I went over. And he left me. And I was drunk and it was strong (heroin) ... and sometimes you just don't know ... sometimes it's just like roulette innit ... like chance and all that bollocks (resignedly). And I went over and he left me. One of the neighbours came out and saw me -and I woke up in the hospital. Oh. My. Gosh. When I see'd him the next time, I ripped him to pieces man. Idiot! Because you're not supposed to leave (each other). It's supposed to be a safety net, you know what I mean? You're not supposed to leave people that have been using. I know people that have been put in lifts and skirt off man.

(Respondent 015)

In essence, the application of these spatially focused codes of conduct illustrates an 'alternative' spatial economy that 'valorises (drug-taking) relationships between people in particular settings' (Lefebvre 1991: 56, parentheses added for illustration) and establishes consensual behaviour deemed appropriate (or otherwise) for such locations. Accordingly, following/breaking the code of overdose avoidance (in Lefebvrian terms) seeks to confirm/refute particular allegiances within street-based injecting settings.

\section{Discussion: Theorising Drug-Related Harm}

The above account provides an illustration of the way in which Lefebvre (1991) regarded ‘social space as socially produced’ using local networks of IDU as the empirical application. All IDU respondents each perceived BCR as legitimate (and normalised) spaces for drug ingestion as a result of having no other viable street-based alternative, (legal or otherwise). 
Furthermore, due to the regular, systemised and habituated attendance by IDU within BCR, all associated spatial practices (access, entry, drug administration and exit strategies) become a form of embodied conduct that further contributes to the production of hazardous bodies.

Within the walls of BCR, the spatial practice of IDU prioritises concealment, speed and urgency that ultimately shape harm and hazard. Such 'embodied performances' (Hockey 2010) constitute socially specific spatial practices associated with a contested production of space (architects vs. residents vs. IDU and the respective conceptions and applications of space and spatial conduct). Such conduct however should not be considered as attempts by IDU to deliberately 'self-harm'. Indeed, this view may be substantiated by the widespread cognisance of harm reduction messages articulated by most of the sample during the study. Instead, harm emerges from attempts to maximise limited opportunities for drug administration, to address dependency/withdrawal and subsequently exit premises 'feeling well' once more without a loss of liberty. Accordingly, the spatial contestation that emerges from the dialectic between representations of space (that of authority and residents) and representational space (of IDU) within HRF poses a significant challenge for harm reduction practitioners.

The above account of injecting drugs in the shared, socially-situated spaces of HRF has identified a wide range of harms that are socially-produced by IDU. These include overdose; exposure to blood borne virus, bacterial infection and unsanitary conditions that lack basic (and essential) amenity to facilitate injecting hygiene. Furthermore, other socially-produced harm in these spatial settings may include self-administered (and peer-mediated) injecting injury, potential viral infection caused by direct needle sharing and the long term health consequences caused by inappropriate (or unhygienic) injecting technique. Whilst these 
harms should not be considered as unique to injecting drug use per se, it is important to note that they do reflect hazards that are consistent with public settings appropriated for injecting purposes. Indeed, these findings would appear confirmatory of a hierarchical framework, known as 'the continuum of descending safety' (Parkin 2009, Parkin and Coomber 2009b, Pearson, Parkin and Coomber 2011), in which the socio-spatial dynamics of place influence and amplify particular drug-related harms.

Accordingly, harms originate and emerge from the social organisation of drug use that occurs within injecting environments including those described throughout this paper. That is, BCR are regarded as providing needful, temporary and concealed settings for the rapid administration of particular drugs. Attendance at such locations is a means of acquiring limited privacy to perform intimate acts that are out of public / police view. However, the need to avoid detection and interruption whilst attending a building in which IDU may have no legitimate right of access, results in a rapid process of drug preparation and injection. These processes are further problematised by individual levels of anxiety, nervousness, paranoia and excitement, each of which further relate to avoiding detection in public places and a need to suitably address drug dependency. Accordingly, the ingestion of drugs becomes intensified in which substances are administered quickly to facilitate a hasty departure from the scene of drug taking. In this manner, hazardous and harmful injecting procedures become embodied within the IDU collective. Furthermore, such spatial practice is regarded as cohesive and logical conduct that legitimises BCR attendance, addresses individual wellbeing and safeguards liberty (from arrest and detention). 


\section{Implications for Policy and Practice}

The harms described above were noted within a sample of IDU who were each familiar with basic harm reduction advice. However, the theory and practice of harm reduction within 'representational spaces' becomes inconsistent with the 'spatial practice' of IDU. Similarly, most of those interviewed recognised the importance of cleanliness and hygiene during preparation and injection, but they also recognised that accessing rooms designed for garbage disposal was practice counter to basic harm reduction advice. Accordingly, for street-based injectors 'absolute harm reduction' becomes a goal difficult to achieve in which the advocated standards of hygiene and preparation possibly serve to emphasise 'hypersanitary messages' (Bourgois et al 1997; 160-161) attached to such optimistic intervention. In short, existing harm reduction strategies may not necessarily reflect the lived-experience of 'spatially constructed' and ‘socially produced' injecting drug use.

Instead, practitioners should perhaps note the way in which IDU re-constructions of PIS amend attempts at an applied harm reduction practice on both an individual and collective level. For example, adaptations to the unhygienic settings described above illustrate attempts by street-injectors to apply the principles of harm reduction within modified settings. However, the structural constraints described by Rhodes et al (2005) pertaining to substance use per se within the wider setting (i.e. laws, policies and practice contained within the macro-environment) serve to severely delimit all opportunities for the safer injecting use of illicit drugs in socially re-constructed settings (at a micro-environment level).

BCR may be considered as an example of socially contested spaces that both produce and reproduce known harms and hazards associated with injecting drug use. Furthermore, these harms become further amplified due to a general awareness of harm reduction intervention 
known (but not fully applied) by IDU attending such venues. As such, these settings of public injecting drug use and the correlations of harm perhaps further illustrate the normalised and embodied conditions that IDU are prepared to endure as a response to having no other practical alternative. Accordingly, in a somewhat fatalistic representation of Lefebvre's spatial trialectic, IDU attempts at harm reduction within their re-constituted injecting spaces (representational space) may become more akin to efforts of actual harm production.

\section{Producing Spaces of Harm Reduction?}

In conclusion, Lefebvre (1991) further suggests that buildings per se should be viewed as an integral component of both the urban and social landscape, in which they are interpreted socially, politically and symbolically. Lefebvre terms urban landscapes as 'archi-texture' (as opposed to architecture) as the city environment provides a canvas that is shaped, produced and read by populations within. This is perhaps a significant aspect within Lefebvre's thesis as it suggests that buildings ('places') contribute to agency, in which space is a container that is never empty, continuously subject to production, recreation and re-interpretation. These ‘social proxemics’ (Lefebvre 1991: 56) perhaps become more apparent when conventions of space are subverted or challenged (by injecting drug use, for example). In this way, Lefebvre argues that 'space indeed 'speaks”' (and) decides what activity may occur' (ibid: 142-43) within spaces conceived as governable.

For these reasons, there is perhaps a need to proactively and positively disrupt the way in which populations of IDU establish harmful drug injecting environments in meaningful attempts to reduce drug-related hazard and injury (Parkin and Coomber 2010). Such measures need not be so ambitious that they become unattainable. Instead, a wide range of options are available that may be considered by the relevant authorities for application within 
similar social-housing projects described throughout this work. For example, the discrete installation of syringe vending machines alongside drug-related litter ('sharps') bins would aim to facilitate health promotion and harm reduction in environments affected by public injecting. Although controversial, such initiatives have long been used in localised public health campaigns (Islam and Conigrave 2007, Moore and Dietze 2005) and 'sharps bins' in public settings have been endorsed by the UK government's Department for Food and Rural Affairs (DEFRA 2005) as an example of good practice. Other more proactive (and less reactive) responses may involve the application of 'more assertive' outreach by peer collectives (in association with relevant service providers) in which injecting equipment may be legitimately distributed in the settings 're-constructed' and appropriated for public injecting purposes (Inman 2011). Similarly, such proactive outreach work would provide increased opportunities for relevant engagement with IDU and associated intervention by drug services. Indeed, when applied in the context of BCR settings, all of the above suggestions would seek to increase safety and reduce harm in a manner that transforms and modifies injecting spaces by a process of enablement (Duff 2009, Moore and Dietze 2005).

However, in the context of public injecting drug use, perhaps the zeniths of formalised disruption are those interventions known as ‘safer injecting facilities’ (or drug consumption rooms). Within such settings, injecting drug use is the raison d'être for the social production of social space. Accordingly, the street-based harms outlined above have been significantly addressed within medically supervised, sanctioned settings (Fairbairn et al 2008, Fast et al, 2008, Freeman et al 2005, Haemmig and Van Beek 2005, Kerr et al 2006, Malkin 2001, Salmon et al 2009, 2010, Stoltz et al 2007, van Beek et al 2004, Wood et al 2004) that, in turn, contribute towards a more considered harm reduction policy. 
What is perhaps most significant in the present setting is that safer injecting facilities originally developed and emerged in locations that were characterised by open drug markets and/or public injecting (or both). Such similarities and correlations have been noted and described in this paper in which BCR represent socially-constructed injecting spaces adjacent established drug markets (sellers) and distributors of injecting equipment (needle/syringe programmes). Similarly, as also demonstrated throughout this paper, drug-related harm and hazard does evidently emerge within unhygienic environments temporarily appropriated by IDU. Accordingly, the findings described above perhaps suggest there is a continued and renewed need for UK policy-makers to review the case for more innovative harm reduction responses in communities affected by public injecting drug use. 'Safer injecting facilities' do not currently exist throughout the UK and would appear as a notable absence in attempts to establish a more fully-comprehensive, harm reduction strategy. This absence may only perpetuate the two colliding constructs of city space as defined by Lefebvre, in which attempts to obtain 'rights to the city' denied to a distinctly marginalised group will invariably contribute to the persistence of drug-related harm in the places socially produced by injecting drug users. Indeed, and to paraphrase Lefebvre (1996), 'the rights to (safer injecting facilities) is like a cry and a demand'.

\section{Acknowledgements / Disclaimer}

The views expressed in this paper are those of the authors and do not necessarily represent those of the University of Plymouth, the agency responsible for funding this research (Barking and Dagenham Drug and Alcohol Action Team) or any other body/organisation associated with the Drug and Alcohol Unit. The authors declare no conflict of interest and would like to thank the two anonymous reviewers, who each provided constructive and informative comments on this paper. 


\section{References}

Beltrano, V., 2009. Informal Publics: Observations on how the creative act of street-vending asserts a collective right to the city. Canadian Architect 3, 42.

Bourdieu, P., 1977. Outline of a Theory of Practice. Cambridge University Press, Cambridge.

Bourdieu, P., 1990. The Logic of Practice. Polity Press, Cambridge.

Bourgois, P., Lettiere, M., Quesada, J., 1997. Social Misery and the Sanctions of Substance Abuse: Confronting HIV Risk Amongst Homeless Heroin Addicts in San Francisco. Social Problems 44, 155-173.

Bourgois, P., Schonberg, J., 2009. Righteous Dopefiend. University of California Press, Berkeley.

Darke, S., Kaye, S., Ross, J., 2001. Geographical injecting locations among injecting drug users in Sydney, Australia. Addiction 96, 241-246.

DeBeck, K., Small, W., Wood, E., Li, K., Montaner, J.S.G., Kerr, T., 2009. Public injecting among a cohort of injecting drug users in Vancouver, Canada. Journal of Epidemiology and Community Health 63, 81-86.

Dovey, K., Fitzgerald, J., Choi, Y., 2001. Safety becomes danger: dilemmas of drug-use in public space. Health and Place 7, 319-331.

Duff, C., 2009. The drifting city; the role of affect and repair in the development of 'enabling environments'. International Journal of Drug Policy 20, 202-208.

Fairbairn, N., Small, W., Shannon, K., Wood, E., Kerr, T., 2008. Seeking refuge from violence in street-based drug scenes: Women's experiences in North America's first supervised injection facility. Social Science and Medicine 67, 817-823.

Fast, D., Small, W., Wood, E., Kerr, T., 2008. The perspectives of injection drug users regarding safer injecting education delivered through a supervised injecting facility. Harm Reduction Journal 5, 32.

Fawaz, M., 2009. Neoliberal Urbanity and the Right to the City: A View from Beirut's Periphery. Development and Change 40, 827-852.

Fitzgerald, J.L., 2005. Policing as public health menace in the policy struggles over public injecting. International Journal of Drug Policy 16, 203-206.

Fitzgerald, J., Dovey, K., Dietze, P., Rumbold, G., 2004. Health outcomes and quasisupervised settings for street injecting drug use. International Journal of Drug Policy 15, 247 $-257$.

Freeman, K., Jones, C.G.A., Weatherburn, D.J., Rutter, S., Spooner, C., Donnelly, N., 2005. The impact of the Sydney Medically Supervised Injecting Centre (MSIC) on crime. Drug and Alcohol Review 23, 173-184. 
Friedman, S.R., Furst, R.T., Jose, B., Curtis, R., Neaigus, A., Des Jarlais, D.C., Goldstein, M.F., Ildefonso, G., 1998. Drug scene roles and HIV Risk. Addiction 93, 1403-1416.

Fry, C.L., 2002. Injecting drug user attitudes towards rules for supervised injecting rooms: implications for uptake. International Journal of Drug Policy 13, 471-476.

Gossop, M., Griffiths, P., Williamson, S., Fountain, J., Strang, J., 1997. Continuing drug risk behaviour: shared use of injecting paraphernalia among London heroin injectors. AIDS Care 9, 651-660.

Green, T., Hankins, C., Palmer, D., Boivin, J.-F., Platt, R., 2003. Ascertaining the need for a Safer Injecting Facility (SIF): the burden of public injecting in Montreal, Canada. Journal of Drug Issues, 713-732.

HM Government, 2008. Drugs: protecting families and communities: The 2008 drug strategy. Home Office, London.

Haemmig, R., Van Beek, I., 2005. Supervised Injecting Rooms. In: Pates, R., McBride, A., Arnold, K. (Eds.), Injecting Illicit Drugs. Blackwell Publishing (Addiction Press), London.

Hanley, S. 2008. Estates: An Intimate History. Granta Books, London.

Hockey, J., 2009. 'Switch on': sensory work in the infantry. Work, Employment and Society 23, 477-493.

Hunt, N., Lloyd, C., Kimber, J., Tompkins, C., 2007. Public injecting and willingness to use a drug consumption room among needle exchange programme attendees in the UK. International Journal of Drug Policy 18, 62-65.

Inman, M., 2011. Drug-user patrols plan. The Canberra Times. 23 January 2011

Islam, M.M., Conigrave, K.M., 2007. Syringe vending machines as a form of needle syringe programme: advantages and disadvantages. Journal of Substance Use 12, 203-212.

Kerr, T., Stoltz, J., Tyndall, M.W., Li, K., Zhang, R., Montaner, J.S.G., Wood, E., 2006. Impact of a medically supervised injection facility on community drug use patterns: a before and after study. British Medical Journal 332, 220-222.

Klee, H., 1997. Amphetamine Injecting Women and Their Primary Partners: An Analysis of Risk Behaviour. In: Catalan, J., Sherr, L., Hedge, B. (Eds.), The Impact of AIDS: Psycological and Social Aspects of HIV Infection. Harwood Academic Publishers, Amsterdam. pp. 115-126.

Layard, A., 2010. Shopping in the Public Realm: A Law of Place. Journal of Law and Society 37, 412-441.

Lefebvre, H., 1991. The Production of Space. Blackwell Publishing, Oxford.

Lefebvre, H. 1996. Writing on Cities. Blackwell Publishing, Oxford. 
Malkin, I., 2001. Establishing Supervised Injecting Facilities: A Responsible Way to Minimise Harm. Melbourne University Law Review 25, 680-756.

Marshall, B.D., Kerr, T., Qi, J., Montaner, J.S.G., Wood, E., 2010. Public injecting and HIV risk behaviour among street-involved youth. Drug and Alcohol Dependence 110, 254-258.

McCann, E.J., 1999. Race, Protest and Public Space: Contextualizing Lefebvre in the US City. Antipode 31, 163-184.

McKnight, I., Maas, B., Wood, E., Tyndall, M.W., Small, W., Lai, C., Montaner, J.S.G., Kerr, T., 2007. Factors associated with public injecting among users of Vancouver's Supervised Injecting Facility. American Journal of Drug and Alcohol Abuse 33, 319-326.

Mitchell, D., 2003. The Right to the City: Social Justice and the Fight for Public Space. The Guilford Press, London.

Moore, D., Dietze, P., 2005. Enabling environments and the reduction of drug-related harm: re-framing Australian policy and practice. Drug and Alcohol Review 24, 275-284.

Nagle, J., 2009. Sites of Social Centrality and Segregation: Lefebvre in Belfast, a "Divided City”. Antipode 41, 326-347.

Navarro, C., Leonard, L., 2004. Prevalence and factors related to public injecting in Ottawa, Canada: implications for the development of a trial safer injecting facility. International Journal of Drug Policy 15, 275 - 284.

Parkin, S., 2009. The Effects of Place on Health Risk: A Qualitative Study of Micro-injecting Environments (PhD Thesis). Faculty of Health. University of Plymouth, Plymouth.

Parkin, S., 2010. Habitus and the Logic of Practice in the Field of Public Injecting Drug Use. Paper Presentation at British Sociological Association Annual Conference, Glasgow Caledonian University, Glasgow. 7-9 April.

Parkin, S., Coomber, R., 2009a. 'Informal Sorter Houses': A Qualitative Insight of the 'Shooting Gallery' Phenomenon in a UK Setting. Health and Place 15, 981-989.

Parkin, S., Coomber, R., 2009b. Public Injecting and Symbolic Violence. Addiction Research and Theory 17, 390-405.

Parkin, S., Coomber, R., 2010a. Fluorescent Blue Lights, Injecting Drug Use and Related Health Risk: Findings from a Qualitative Study of Micro-Injecting Environments. Health and Place 16, 629-637.

Parkin, S., Coomber, R., 2010b. A Rapid Appraisal of Public Injecting and Drug Related Litter in the London Borough of Barking and Dagenham. University of Plymouth, Plymouth.

Parkin, S., Coomber, R., Wallace, G., 2010. Going Public. Drink and Drug News, London. pp. 14-15. 
Pearson, M., Parkin, S., Coomber, R., 2011. The transferability of harm reduction via a streetbased typology developed through qualitative research. Contemporary Drug Problems, 38.

Rhodes, T., 2002. The 'risk environment': a framework for understanding and reducing drugrelated harm. International Journal of Drug Policy 13, 85-94.

Rhodes, T., Singer, M., Bourgois, P., Friedman, S.R., Strathdee, S.A., 2005. The social structural production of HIV risk among injecting drug users. Social Science and Medicine 61, 1026-1044.

Rhodes, T., Watts, L., Davies, S., Martin, A., Smith, J., Clark, D., Craine, N., Lyons, M., 2007. Risk, shame and the public injector: a qualitative study of drug injecting in South Wales. Social Science and Medicine 65, 572-585.

Rhodes, T., Zikic, B., Prodanovic, A., Kuneski, E., Bernays, S., 2008. Hygiene and uncertainty in qualitative accounts of hepatitis $\mathrm{C}$ transmission among drug injectors in Serbia. Social Science and Medicine 66, 1437-1447.

Salmon, A.M., Dwyer, R., Jauncey, M., Van Beek, I., Topp, L., Maher, L., 2009. Injectingrelated injury and disease among clients of a supervised injecting facility. Drug and Alcohol Dependence 101, 132-136.

Salmon, A.M., Van Beek, I., Amin, J., Kaldor, J., Maher, L., 2010. The impact of a supervised injecting facility on ambulance call outs in Sydney, Australia. Addiction 105, 676683.

Small, W., Rhodes, T., Wood, E., Kerr, T., 2007. Public injection settings in Vancouver: physical environment, social context and risk. International Journal of Drug Policy 18, 2736.

Stoltz, J., Wood, E., Small, W., Li, K., Tyndall, M., Montaner, J.S.G., Kerr, T., 2007. Changes in injecting practices associated with the use of a medically supervised safer injection facility. Journal of Public Health 29, 35-39.

Taylor, A., Cusick, L., Kimber, J., Rutherford, J., Hickman, M., Rhodes, T., 2006. The social impact of public injecting (Independent Working Group on Drug Consumption Rooms). Joseph Rowntree Foundation. p. Paper D.

Taylor, A., Fleming, A., Rutherford, J., Goldberg, D., 2004. Examining the injecting practices of injecting drug users in Scotland. Effective Interventions Unit, Scottish Office, Edinburgh.

van Beek, I., Kimber, J., Dakin, A., Gilmour, S., 2004. The Sydney Medically Supervised Injecting Centre: reducing harm associated with heroin overdose. Critical Public Health 14, 391-406.

Wood, E., Kerr, T., Small, D., Li, K., Marsh, D.C., Montaner, J.S.G., Tyndall, M.W., 2004. Changes in public order after the opening of a medically supervised safer injecting facility for illicit injection drug users. Canadian Medical Association Journal 171, 731-734. 
Appendix 1. Table 1: Rapid appraisal methods, sources of evidence and data collection procedures

\begin{tabular}{|c|c|}
\hline Method & Purpose \\
\hline $\begin{array}{c}\text { Ethnography and } \\
\text { Participant } \\
\text { Observation }\end{array}$ & $\begin{array}{l}\text { 1. To obtain rich descriptions of naturally occurring events in } \\
\text { community settings } \\
\text { 2. To observe community issues and problems from the } \\
\text { perspective of objective researcher }\end{array}$ \\
\hline $\begin{array}{l}\text { Environmental Visual } \\
\text { Assessments } \\
\text { (visits to settings of } \\
\text { public injecting drug } \\
\text { use with agency } \\
\text { representatives and } \\
\text { an injecting drug } \\
\text { user) }\end{array}$ & $\begin{array}{l}\text { 1. To become familiar with environments used for injecting } \\
\text { purposes and consider these settings from a harm reduction } \\
\text { perspective } \\
\text { 2. To gain an understanding of the varied environmental } \\
\text { conditions used for injecting drug use } \\
\text { 3. To obtain the views of community residents/various } \\
\text { employees affected by public injecting issues and to note } \\
\text { official responses } \\
\text { 4. To obtain an insight of how public injecting is policed and } \\
\text { managed } \\
\text { 5. To compare interview data with environmental setting } \\
\text { 6. To visually record (photograph) key settings used for public } \\
\text { injecting drug use } \\
\text { 7. To provide advice and information on public injecting } \\
\text { issues }\end{array}$ \\
\hline $\begin{array}{l}\text { Informal, semi- } \\
\text { structured interviews } \\
\text { with } 63 \text { agency } \\
\text { representatives }\end{array}$ & $\begin{array}{l}\text { 1. To gain an understanding of public injecting from a variety } \\
\text { of experiences } \\
\text { 2. To obtain insights of the way in which public injecting } \\
\text { affects various 'workplaces' and residential settings } \\
\text { 3. To understand official responses to public injecting issues } \\
\text { 4. To consider drug related litter within each of the above } \\
\text { 5. To identify any barriers to harm reduction practice }\end{array}$ \\
\hline $\begin{array}{l}\text { Informal, semi- } \\
\text { structured interviews } \\
\text { with } 20 \text { injecting drug } \\
\text { users }\end{array}$ & $\begin{array}{l}\text { 1. To assess the rationale, motivation and experiences of } \\
\text { public injecting from those previously or currently involved } \\
\text { in such activity } \\
\text { 2. To consider the impact of public injecting upon individual } \\
\text { and public health } \\
\text { 3. To identify harms and hazards experienced associated with } \\
\text { public injecting } \\
\text { 4. To elicit user views on service development as a response } \\
\text { to public injecting } \\
\text { 5. To assist in the identification of frequent settings of public } \\
\text { injecting }\end{array}$ \\
\hline $\begin{array}{c}\text { Quantitative Data } \\
\text { Analysis }\end{array}$ & $\begin{array}{l}\text { 1. To note the frequency and volume of needle/syringe } \\
\text { distribution and return } \\
\text { 2. To note the frequency and volume of drug related litter in } \\
\text { community settings } \\
\text { 3. To compare qualitative accounts relating to specific datasets }\end{array}$ \\
\hline
\end{tabular}


Appendix 2. Table 2: Demographics (percentages in parenthesis)

\begin{tabular}{|c|c|c|c|}
\hline Field & Male & Female & Sample \\
\hline Gender & $14(70)$ & $6(30)$ & $20(100)$ \\
\hline Age (range) & 23-47 years old & 24-45 years old & 23-47 years old \\
\hline Age (average) & 36 years old & 31 years old & 33.5 years old \\
\hline White (British) & $9(45)$ & $6(30)$ & $15(75)$ \\
\hline $\begin{array}{l}\text { Black and Minority } \\
\text { Ethnic (British) }\end{array}$ & $5(25)$ & 0 & $5(25)$ \\
\hline Born Local & $13(65)$ & $6(30)$ & $19(95)$ \\
\hline Barking Resident & $8(40)$ & $2(10)$ & $10(50)$ \\
\hline Dagenham Resident & $6(30)$ & $4(20)$ & $10(50)$ \\
\hline Receipt of Benefits & $13(65)$ & $6(30)$ & $19(95)$ \\
\hline Employment & $2(10)$ & 0 & $2(10)$ \\
\hline Ever L.A. Care & $4(20)$ & 0 & $4(20)$ \\
\hline Ever Home/Roof-less & $12(60)$ & $6(30)$ & $18(90)$ \\
\hline Ever Prison (DRO*) & $11(55)$ & $3(15)$ & $14(70)$ \\
\hline Ever Sex Work & $2(10)$ & $2(10)$ & $4(20)$ \\
\hline Current Sex Work & 0 & $2(10)$ & $2(10)$ \\
\hline $\begin{array}{l}\text { Sex Work in Years } \\
\text { (range) }\end{array}$ & Missing & $1-5$ years & 1-5years \\
\hline
\end{tabular}

*for drug-related offences (DRO) 
Appendix 3. Table 3: Drug Use History (percentages in parenthesis)

\begin{tabular}{|c|c|c|c|}
\hline Field & Male & Female & Sample \\
\hline Gender & $14(70)$ & $6(30)$ & $20(100)$ \\
\hline Current Injector & $9(45)$ & $4(20)$ & $13(65)$ \\
\hline Heroin (main drug) & $11(55)$ & $2(10)$ & $13(65)$ \\
\hline Heroin / Crack (main drug) & $4(20)$ & $3(15)$ & $7(35)$ \\
\hline $1^{\text {st }}$ IDU (average age) & 25 years old & 24 years old & 24.5 years old \\
\hline $1^{\text {st }}$ IDU (range) & 17-40 years old & 19-33 years old & $17-40$ years old \\
\hline Injecting Career (average) & 11 years & 6 years & 9 years \\
\hline Treatment (current) & $12(60)$ & $5(25)$ & $17(85)$ \\
\hline $\begin{array}{lll}\begin{array}{l}\text { Average Daily } \\
\text { (Methadone) }\end{array} & \text { Dose } \\
\end{array}$ & 55 mils & 25 mils & 48 mils \\
\hline $\begin{array}{ll}\text { Daily Dose Range } \\
\text { (Methadone) }\end{array}$ & 30-80 mils & 17-35 mils & 17-80 mils \\
\hline Ever Rehab/Detox & $7(35)$ & $3(15)$ & $10(50)$ \\
\hline Ever Overdose (indoors) & $6(30)$ & $2(10)$ & $8(40)$ \\
\hline Ever Overdose (outdoors) & $7(35)$ & $2(10)$ & $9(45)$ \\
\hline $\begin{array}{l}\text { Ever Witness Overdose } \\
\text { (indoors) }\end{array}$ & $8(40)$ & $4(20)$ & $12(60)$ \\
\hline $\begin{array}{l}\text { Ever Witness Overdose } \\
\text { (outdoors) }\end{array}$ & $10(50)$ & $3(15)$ & $13(65)$ \\
\hline Ever Public Injecting & $14(70)$ & $6(30)$ & $20(100)$ \\
\hline
\end{tabular}


Appendix 4. Photo 1: A typical bin chute room.

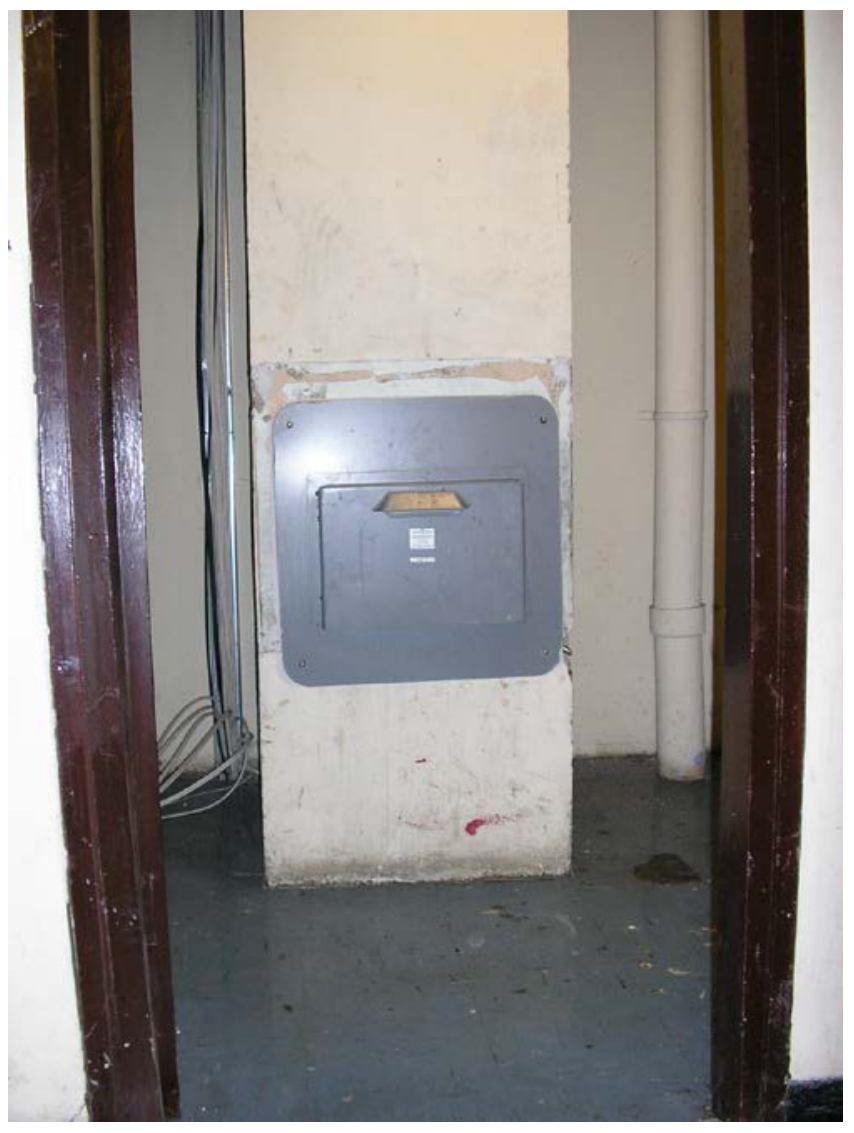

